\section{The first report of pure neuritic leprosy with involvement of the anterior femoral cutaneous nerve}

\author{
Francisco Bezerra de Almeida Neto, ${ }^{1-3}$ \\ Raul Aureliano Neto, 1 \\ Lucas Machado Carvalho Cardoso 1 \\ 1Department of Dermatology, Maurício \\ de Nassau University Center, Recife; \\ 2Department of Tropical Medicine, \\ Federal University of Pernambuco \\ (UFPE), Pernambuco; 3Dermatology, \\ Leprology and Venereology Department, \\ Herbert de Souza Health Care Center - \\ Cabo de Santo Agostinho, Pernambuco, \\ Brazil
}

\begin{abstract}
We describe the case of a young man, 22 years old, a household contact of leprosy, presenting paresthesia in the right leg and great thickening in the anterior femoral nerve and in the ipsilateral sural nerve. There were no typical dermatological lesions of leprosy. Ultrasonography confirmed the clinical finding. The clinical diagnosis of the disease was established and the patient started multibacillary-multidrug therapy, obtaining improvement of the initial symptomatology.
\end{abstract}

\section{Case Report}

A 22-year-old man had a complaint of "dilated vein and leg numbness" for about 3 months. Physical examination revealed the presence of a fibrotic consistency linear structure in the medial third of the right thigh, slightly painful to the palpation (Figure 1). There was thickening of the common fibular nerve trunk at palpation and of the ipsilateral sural nerve without any evidence of dermatological lesions. Ultrasonographic examination demonstrated an important increase in the volume of the superficial branch of the anterior right femoral nerve and of the sural nerve, consistent with a peripheral neuropathy (Figure 2 ). The patient was a household leprosy contact, and his parent had completed treatment for lepromatous leprosy for approximately 5 years. The slit-skin smear was negative and the laboratory tests were normal. The diagnosis of primary neural leprosy was established and the patient started treatment with multibacillary-multidrug therapy (MDT-MB), with a progressive reduction of the thickening of the affected nerves and also of the symptoms.

\section{Discussion}

Leprosy is an infectious disease caused by Mycobacterium leprae and Mycobacterium lepromatosis, which affects the skin, the peripheral nerves and also organs and systems. There are clinical cases of leprosy that escape the classical recognition and diagnosis of the disease based on the Ridley-Jopling classification, due to the fact that the patients do not present cutaneous lesions but only neurological manifestations consistent with the involvement of the peripheral nerves. 1,2

Wade (1952) recognized this clinical form of leprosy as an isolated subtype in the classification of the disease, grouping these patients into the "polyneuritic group" with the subdivision "primary polyneuritic group".3 As of 1988, the World Health Organization and other associations of leprologists throughout the world in subsequent decades recognizes this clinical form of leprosy and corroborates the initial observations of Wade. These cases are called pure (or primary) neuritic leprosy (PNL). ${ }^{4}$

In relation to the most affected nerves in the PNL, despite the heterogeneity of the studies, in order of greater to less prevalence, are highlighted the ulnar nerve, followed by the common fibular, medial, radial and facial. The most frequent pattern of nerve involvement in PNL is that of mononeuropathy, multiple mononeuropathy, and more rarely polyneuropathy cases, which are in fact, confluent mononeuropathies. ${ }^{5}$

Kumar et al. (2004) analyzed 1542 patients in the period between 1993 and 2003 and found 65 cases of HNP (4.2\%). Of these, 39 patients $(60.0 \%)$ had 2 or more affected nerves at the same extremity. In this study, the nerves most frequently affected were the right ulnar and right common fibular nerves. ${ }^{6}$

Mahajam et al. (1996) analyzed 3853 cases of leprosy and found 179 patients (4.6\%) with PNL and also observed the ulnar and common fibular nerves being the most affected. ${ }^{7}$

In Brazil, Santos et al. (2017) observed 70 patients diagnosed with PNL in the period between 2014 to 2016 and the nerves most frequently involved were also ulnar and common fibular nerves. ${ }^{8}$

The lateral femoral cutaneous nerve is formed by afferent sensory fibers, originating from the nerve roots L2 and L3. It crosses the lateral margin of the greater psoas
Correspondence: Francisco Bezerra de Almeida Neto, Avenida Senador Sérgio Guerra, 520/142, Piedade, Jaboatão dos Guararapes - PE. CEP 5440-003, Brazil.

Tel.: +55.81988484442

E-mail: francisban@gmail.com

Key words: Leprosy, pure neuritic leprosy, femoral cutaneous nerve, sural nerve.

Acknowledgements: the authors acknowledge Dr. Fred Nietto (PHD) for contribution to the translation of this manuscript. This study was carried out with the researchers' own resources.

Contributions: the authors contributed equally.

Conflict of interest: the authors declare no potential conflict of interest.

Funding: none.

Received for publication: 27 January 2019. Accepted for publication: 14 April 2019.

This work is licensed under a Creative Commons Attribution NonCommercial 4.0 License (CC BY-NC 4.0).

(C) Copyright F.B. de Almeida Neto et al., 2019 Licensee PAGEPress, Italy

Neurology International 2019; 11:8001 doi:10.4081/ni.2019.8001

and after its division in left and right, which occurs in the intimacy of the pelvis distally to the inguinal ligament, each nervous branch is subdivided into anterior and posterior. The anterior branch leaves the fascia lata a little after the posterior branch, being responsible for the distal antero-lateral sensibility of the thigh until the knee, whose peripatelar innervation is also performed by the infrapatellar branch of the saphenous nerve. Posterior division will be responsible for the proximal sensibility of the lateral aspect of the thigh, in the region above the major trochanter and part of the gluteal skin, extending to the upper half of the thigh. ${ }^{9}$

The main peripheral neuropathy described, capable of affecting the superficial femoral cutaneous nerve, is the paresthetic meralgia. This condition occurs due to pelvic anatomical variations leading to compression. Symptoms may range from pain to paresthesia and anesthesia on the lateral aspect of the thigh. However, there is no neural thickening. ${ }^{10}$

The sural nerve (SN) is also called the short saphenous nerve. It is also a sensitive nerve of the skin. There are six described patterns of anatomical variations regarding the branching and finalization of sural nerve 

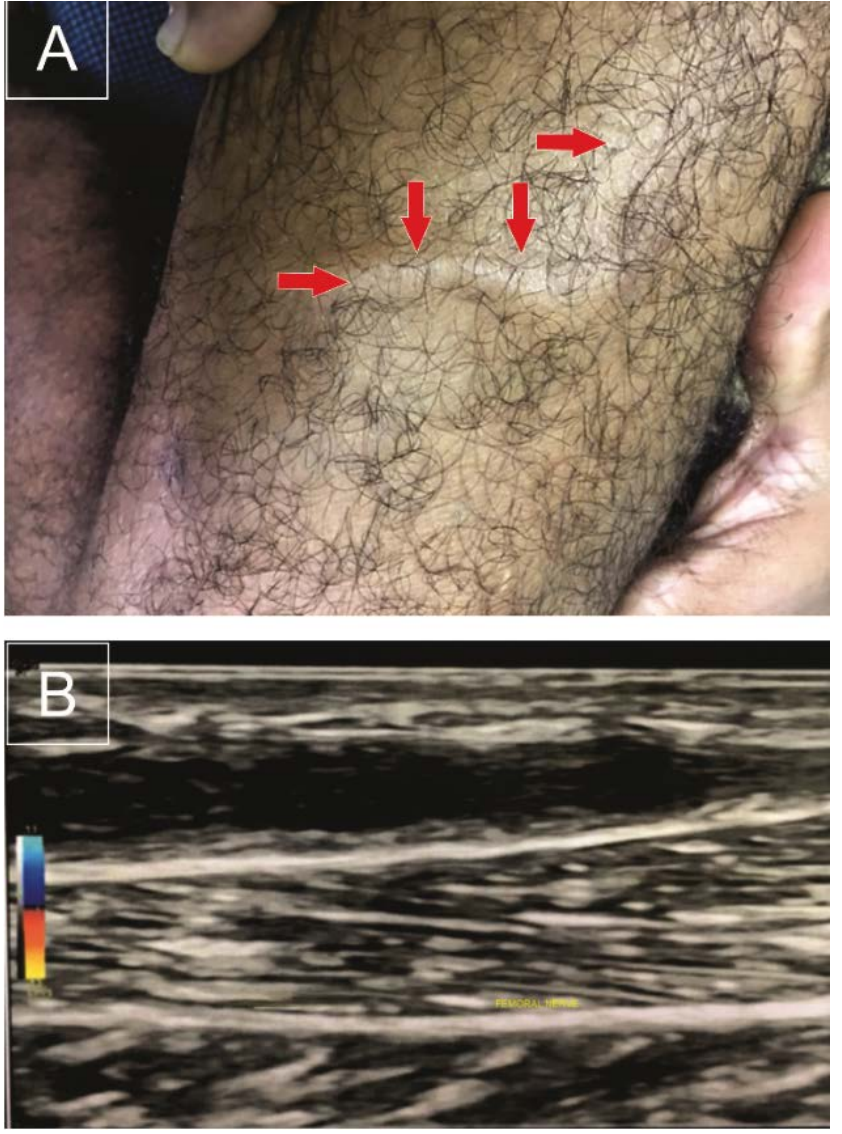

Figure 1. A) Thickening of the superficial femoral cutaneous nerve (arrows); B) ultrasonographic image.
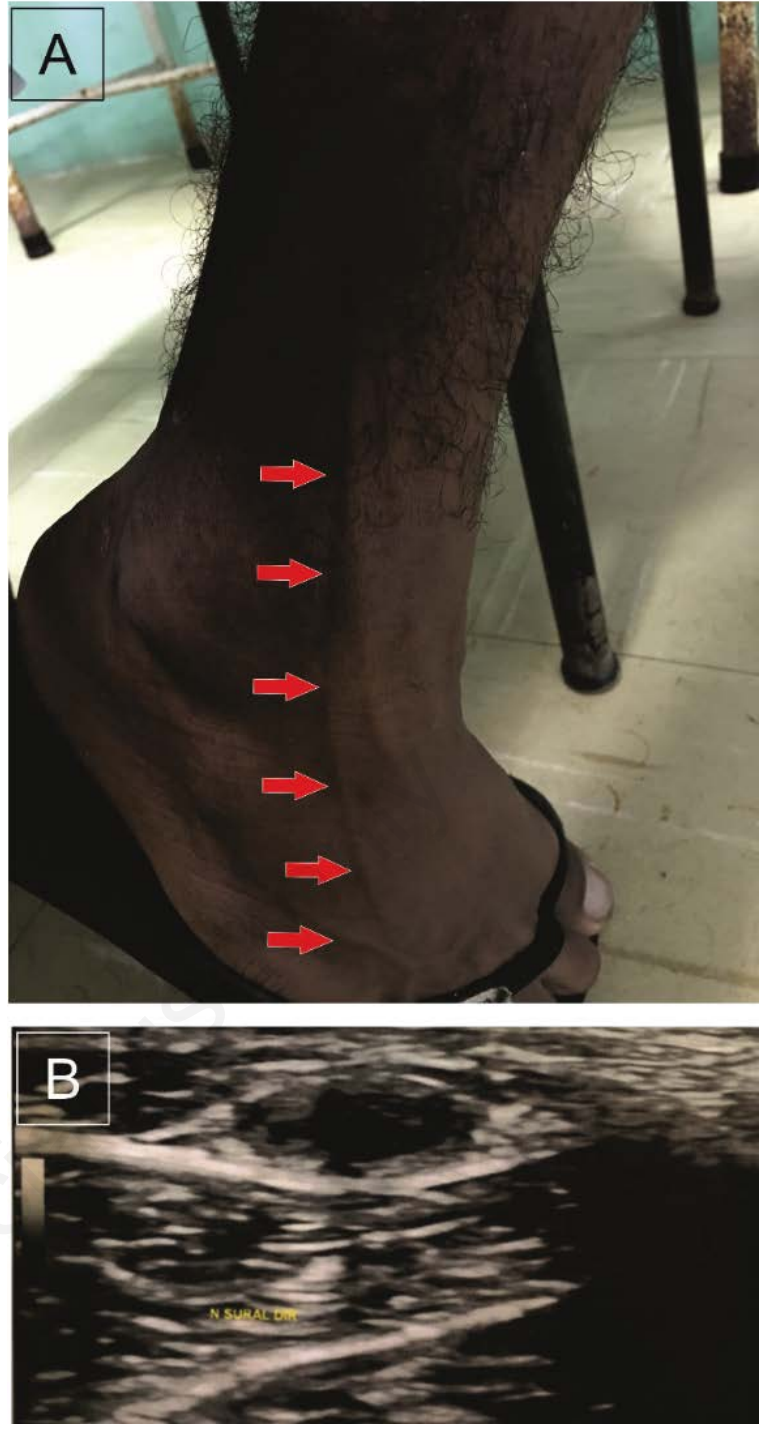

Figure 2. A) Thickening of the sural nerve (arrows); B) ultrasonographic image. endings. As a rule, it originates from the common fibular nerve and is subdivided into two branches: the lateral sural cutaneous nerve, responsible for the sensory innervation of the distal posterolateral third of the foot to the lateral face of the fifth toe, and the cutaneous sural nerve medial, with shorter termination, which is responsible for the sensitivity of the lateral portion of the calcaneal region. ${ }^{11,12}$

The most frequently described neuropathies involving SN are Type 2 Diabetes mellitus, HIV-related neuropathy, and chronic idiopathic axonal demyelinating polyneuropathy. In rare cases of neural compression are described by thickening of the adjacent muscular fascia. The main symptomatology involved in these cases are paresthesia and pain, which may or may not be related to the assumption of certain postures and/or movements. However, there is also no neural thickening in these cases. ${ }^{13-16}$

In cases of PNL due to involvement of the common fibular nerve, involvement of its branches, including $\mathrm{SN}$, is also relatively frequent. This SN involvement is accompanied by paresthesia, anesthesia and pain in corresponding dermatomes, with subsequent neural thickening. ${ }^{17}$

The patient under discussion, in addition to having a family history of leprosy, lives in a hyperendemic area for the disease, and the diagnosis was corroborated by the anamnesis, physical and ultrasound examination, highlighting the great increase in the volume of the affected nerves.

The diagnosis of PNL is eminently clinical, with neural thickening being its most evident manifestation. The tests that can be used are mainly the histopathological study of the nerve, which can be performed by conventional neural biopsy or aspiration.
The findings are nonspecific and merely suggestive of the disease, being considered corroborating when the bacillus is encountered, which rarely occurs. ${ }^{18,19}$

In PNL, patients evolve without apparent cutaneous lesions. In a few cases, these lesions may arise after the initiation of MDT treatment or in reactional episodes. To be classified as having PNL, slit-skin smear must be negative. These factors can provide a delay in the identification of the disease, with the consequent incapacities and sequels subsequent to the late diagnosis. ${ }^{20}$

\section{Conclusions}

This clinical case is the first report of the involvement of the superficial femoral cutaneous nerve as a manifestation of leprosy. PNL is often a true diagnostic chal- 
lenge, being confused with numerous other conditions that compromise the peripheral nervous system. In countries endemic to leprosy such as Brazil, or in immigrant patients from these localities, any clinical manifestation involving the peripheral nervous system, may have a primordial genesis in leprosy.

\section{References}

1. Han XY, Seo YH, Sizer KC. A new Mycobacterium species causing diffuse lepromatous leprosy. Am J Clin Pathol 2008;130:856-64.

2. Ridley DS. Jopling WH. Classification of leprosy according to immunity- a five-group system. Int $\mathrm{J}$ Lepr Other Mycobact Dis. Int $\mathrm{J}$ Lepr Other Mycobact Dis 1966;34:255-73.

3. Wade HW. The classification of leprosy: a proposed synthesis based primarily on the Rio de Janerio-Havana system. Int J Lepr 1952;20:429-62.

4. World Health Organization. Chemotherapy of leprosy: report of a WHO study group. Geneva: WHO technical report series 847, 1994.

5. Garbino JA, Jardim MR, Marques JRW, et al. Hanseníase Neural Primária. Projeto Diretrizes (AMBCFM) 2011;126.

6. Kumar B, Kaur I, Dogra S, Kumaran
MS. Pure neuritic leprosy in India: an appraisal. Int J Lepr Other Mycobact Dis 2004;72:284-90

7. Mahajan PM, Jogaikar DG, Mehta JM. A study of pure neuritic leprosy: clinical experience. Indian J Lepr 1996;68:13741.

8. Santos DFD, Mendonça MR, Antunes DE, et al. Revisiting primary neural leprosy: Clinical, serological, molecular, and neurophysiological aspects. PLoS Negl Trop Dis 2017;11:e006086.

9. Swezey E, Bhimji SS. Anatomy, Head and Neck, Lateral Femoral Cutaneous Nerve. StatPearls [Internet]. Treasure Island (FL): StatPearls Publishing; 2018.

10. Lee SH, Shin KJ, Gil YC, et al. Anatomy of the lateral femoral cutaneous nerve relevant to clinical findings in meralgia paresthetica. Muscle Nerv. 2017;55:646-50.

11. Ramakrishnan PK, Henry BM, Vikse J, et al. Anatomical variations of the formation and course of the sural nerve: A systematic review and meta-analysis. Ann Anat 2015;202:36-44.

12. Wang F, Zhou D, Li W, et al. A New Pattern of the Sural Nerve Added to "Anatomy of the Sural Nerve: Cadaver Study and Literature Review". Plast Reconstr Surg Glob Open 2017;5:e1628.

13. Mohseni S, Badii M, Kylhammar A, et al. Longitudinal study of neuropathy, microangiopathy, and autophagy in sural nerve: Implications for diabetic neuropathy. Brain Behav 2017;7:e00763.

14. Kaku M, Simpson DM. HIV neuropathy. Curr Opin HIV AIDS 2014;9:5216.

15. Molenaar DS, Vermeulen M, De Haan R. Diagnostic value of sural nerve biopsy in chronic inflammatory demyelinating polyneuropathy. J Neurol Neurosurg Psychiatry 1998;64:84-9.

16. Paraskevas GK, Natsis K, Tzika M, et al. Fascial entrapment of the sural nerve and its clinical relevance. Anat Cell Biol 2014;47:144-7.

17. De Freitas MR, Nascimento OJ, Hahn MD. Isolated superficial peroneal nerve lesion in pure neural leprosy: case report. Arq Neuropsiquiatr 2004;62:535-9.

18. Antunes SL, Chimelli L, Jardim MR, et al. Histopathological examination of nerve samples from pure neural leprosy patients: obtaining maximum information to improve diagnostic efficiency. Mem Inst Oswaldo Cruz 2012;107:24653.

19. Kumar B, Pradhan A. Fine Needle Aspiration Cytology in Diagnosis of Pure Neuritic Leprosy. Patholog Res Int 2011;2011:158712.

20. Jardim MR, Antunes SL, Santos AR, et al. Criteria for diagnosis of pure neural leprosy. J Neurol 2003;250:806-9. 